\title{
Clay-bearing mine tailings analysis and implications in large filter press design
}

\author{
A Grosso Aqseptence Group srl, Italy \\ F Kaswalder Aqseptence Group srl, Italy \\ A Hawkey Aqseptence Group Pty Ltd, Australia
}

\begin{abstract}
Filtered tailings dry stack disposal often requires low cake residual moistures to meet the stacking specifications defined by geotechnical studies. Low residual moisture targets and increasing throughputs require careful definition of filter press process parameters in order to prevent unnecessary extra capital and operating costs.
\end{abstract}

Because of this, alongside the testing phase, a comprehensive characterisation of the material, not limited to standard geotechnical tests, becomes important. Standard physical/chemical characterisation of mining slurries includes both basic (liquor, solid and slurry density, solid concentration, solid specific gravity) and thorough analysis (yield stress, particle size distribution, elements and mineral phase detection). Each of these requires different techniques.

Phyllosilicates (i.e. clays) are one of the most common components of mine tailings, together with quartz, feldspar and other aluminosilicates. Clay type and relative content can have a drastic influence on the filtration process and furthermore on filter design. A detailed analysis of clayey phases can give useful information about the filterability of a slurry and, therefore, on the expected filter performance and its variability. A comprehensive study about clay detection and quantification and correlation with dewatering properties is presented here. It involves different analytical techniques (powder X-ray diffraction, Rietveld refinement, qualitative evaluation) and correlation studies based on the lab testing campaign's database.

The results show how the filterability can be strongly affected by the phyllosilicate type and small variations in their content, to yield completely different cake properties, showing that smectite group clays have the greatest influence on filterability.

The impact of these characteristics on filter sizing, especially for large equipment (like the GHT5000F filter press) and related ancillaries will be discussed.

Keywords: dry stacking, mine tailings, large filter presses, clays, $X$-ray diffraction

\section{Introduction}

\subsection{Clay and mine tailings}

With the rising global demand for minerals (Figure 1) and the reduction of the average mineral grade, mining and mineral processing industries are progressively encountering many more complexities. The result of this confluence is an increasing amount of tailings being generated that must be managed somehow, either by increasing the capacity of existing tailings facilities or, for greenfield sites, designing tailings management solutions of a scale previously unheard of. 


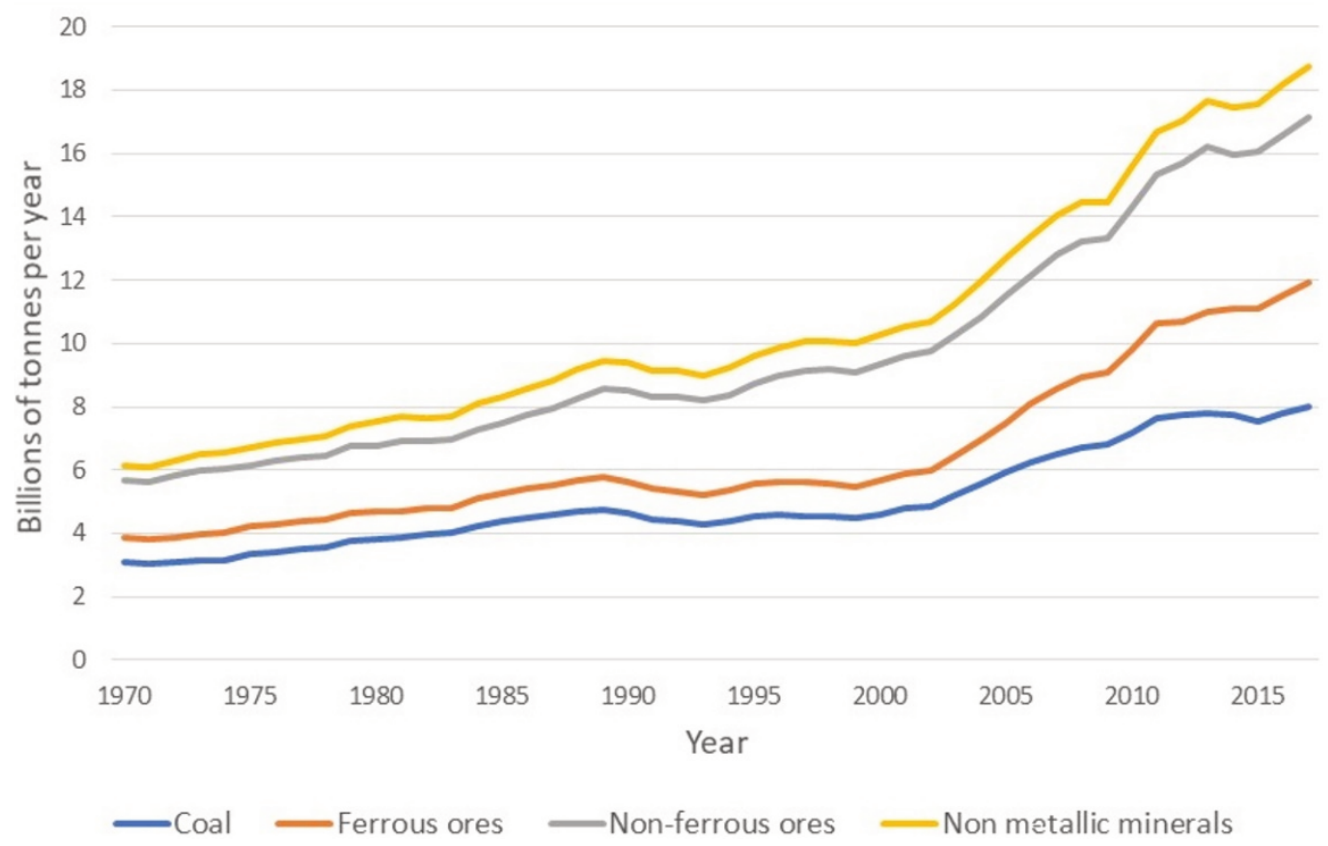

Figure 1 Direct, gross physical extraction by year and commodity (Source: United Nations Environment Programme International Resources Panel 2021)

The increasing amount of tailings generated, together with the lowered average ore grades, have a strong impact on the overall performance of mineral processing plants, especially by affecting the tailings characteristics and their management strategies significantly. The impact of these materials on tailings filtration, necessary to get a final residue that can be stacked, tends to be lower throughputs while producing cakes with higher moisture, making the design of the stack more challenging. At the same time, other parts of the process are affected. For example, in the case of a pyritic gold ore, the presence of $5 \%$ of bentonite-containing clay reduced the flotation recovery of pyrite by $18 \%$, increasing the tailings stream throughput. Therefore, the negative effects of phyllosilicates are ubiquitous throughout the mineral processing industry.

It should be considered, furthermore, that the capacity demand of filtration equipment is rapidly increasing due to a constant rise in the mineral extraction and related tailings throughput. Many projects are currently overcoming 50,000 tonnes per day throughput, while a few feasibility studies reach even higher values, up to 150,000 tonnes per day. Together with high productivities, filtered tailings stack design often requires strict and stable dewatering efficiency, making the filter press one of the most promising separation technologies due to its significant benefits (e.g. low final residual moisture and high capacity achievable).

In the light of the above, a thorough mineralogical characterisation is of the utmost importance both in filter design and process tuning stages.

Clay minerals have particle sizes commonly less than $2 \mu \mathrm{m}$ and are identified as fine-grained phyllosilicate minerals which comprise silicate tetrahedral ' $T$ ' layers and alumina octahedral ' $O$ ' layers as basic building blocks, as shown in Figure 2. T layers are comprised of units in which four oxygen atoms are arranged symmetrically around a silicon atom, and those units are interconnected by a shared apical oxygen atom. In octahedral units, a central cation is bonded to six hydroxyl groups in octahedral symmetry. The central cation in the octahedral unit can be $\mathrm{Al}^{3+}$ or $\mathrm{Mg}^{2+}$. If the cation is $\mathrm{Al}^{3+}$, layers have dioctahedral units while layers consist of trioctahedral units if the cation is $\mathrm{Mg}^{2+}$. Various compilations of $\mathrm{T}$ and $\mathrm{O}$ layers result in the formation of different types of clay minerals with similar structure but different physical and chemical properties. Most clay minerals have either 1:1 TO (e.g. kaolinite), 2:1 TOT (e.g. smectite) or 2:1:1 TOT+O layer arrangement (e.g. chlorite) (Ndlovu et al. 2014). 
TO layer

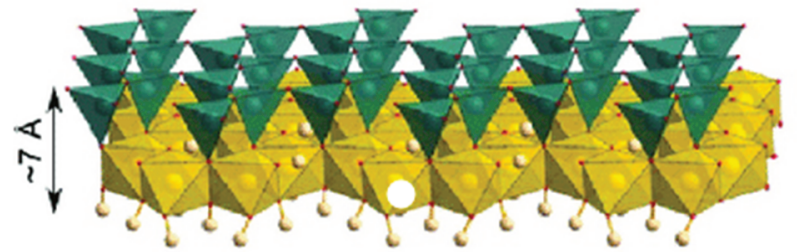

TOT layer

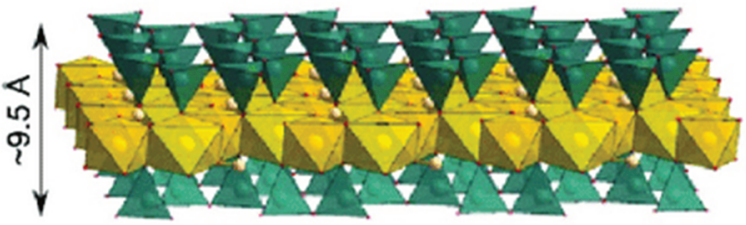

Figure 2 Example of clays packing in TO and TOT layer (Tournassat et al. 2015)

More specifically, a clay mineral consists of a unit cell combining $O$ and $T$ layers, interconnected by primary bonds; the unit cells are interconnected by secondary bonds between them, forming a clay particle (Ndlovu et al. 2014). The degree of isomorphous substitution in smectite group minerals is characteristically high, in contrast to kaolinite. In an aqueous suspension of weakly exchanged smectite, water molecules penetrate the interlayer region where resulting repulsive hydration forces lead to separation of the layers by $10-20 \AA$ (crystalline swelling). Where the exchanged species are monovalent ions such as $\mathrm{Na}^{+}$or $\mathrm{Li}^{+}$, interlayer separations up to several hundred angstroms (osmotic swelling) may result due to high osmotic pressure which arises to overcome the weak van del Waals attraction. The swelling behaviour of the smectite suspensions leads to characteristically poor settling rates (e.g. $<0.1 \mathrm{~m} \mathrm{~h}^{-1}$ ), low sediment solid loading $(<10 \mathrm{wt} \%)$ and increased shear yield stress, the latter of which can mitigate compact consolidation (McFarlane et al. 2006).

\section{Methodology}

There is no single way to prepare materials for X-ray diffraction analysis. Preparation techniques depend on supplies and equipment available, purpose of analysis (qualitative or quantitative identification), and the material itself. Procedures for preparing samples for $\mathrm{X}$-ray diffraction fall into two groups:

- Random powder: perfectly random orientation of the grains is the goal. It is useful, for example, for the identification and quantification of non-clay minerals, for the evaluation of the crystallinity of quartz, and for the determination of some specific crystallographic parameters.

- Oriented powder: perfect orientation of the clay mineral flakes parallel to the substrate is the goal. The analysis of properly treated samples allows, through the exaltation of the basal reflections, the identification of the various clay minerals or groups of them and their abundance ratios (Cavalcante \& Belviso 2005).

In the first case, the target is to see all (hkl) reflections of the mineral or minerals present, with the correct relative intensities of their reflections. This requires perfectly random orientation of the particles of the sample. The plate-like shape of the clay mineral particles makes random orientation difficult to achieve. Most crystal breaks or cleave more readily along some planes than others. When packed as a powder, orientation of individual grains tends to be governed by the juxtaposition of faces formed by these preferential breakages, and this process works against the production of a randomly oriented aggregate. Sample preparations that have no preferred orientation are crucial for quantitative analyses of mixtures of clay and non-clay minerals and for interpretation of diffraction patterns of clay mineral polytypes.

It should be noticed that the main problem in clay phase identification is that, because of their crystal structure, they show very similar patterns, often overlapped on each other. Even by correlating the spectrum with an elemental analysis of the alkaline and/or alkaline earth cations, their complete qualitative discrimination is impossible. In this regard, Figure 3 shows a pattern of an untreated sample, underlining to the low angle spectrum area, in which the characteristic peaks of clayey materials are present. 


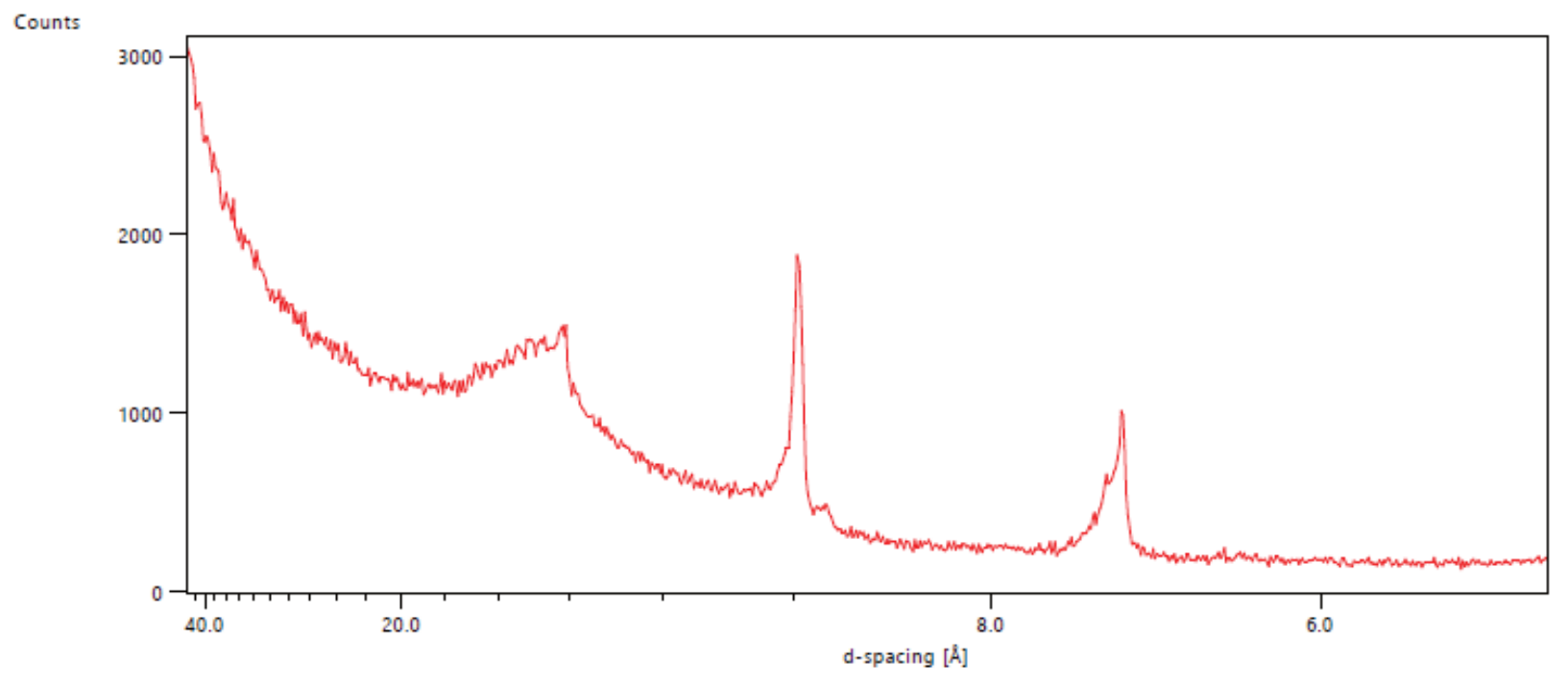

Figure 3 Spectrum of a bulk sample, focusing on low angle area

In Figure 3 , the $14 \AA$ peak can be attributed to different groups of clays such as chlorite, vermiculite or smectite. The peak at $10 \AA$ can be attributed to illite or mica. Finally, the $7 \AA$ peak can be attributed to serpentines, kaolin or chlorite. It is therefore clear that from the single bulk X-ray diffraction (XRD) analysis, it is not possible to discriminate one particular clay from another.

In this work, a multiple step XRD method for crystalline phases identification and quantification is presented; it can be summed up as follows:

1. Collection of a full spectrum of randomly oriented sample.

2. Fine fraction $(<2 \mu \mathrm{m})$ separation, preparation of an XRD specimen that maximises the preferred orientations and collection of an XRD spectrum of the typical clay characteristic peaks region ( $\theta$ between 0 and 20 degrees).

3. Analysis of the spectrum peaks shifting after different chemical-physical treatment of the specimen.

4. Clay phase identification and full phase quantification by means of Rietveld refinement (Altomare et al. 2001).

The sample should be dried, crushed in a mortar (1-2 g) and loaded into a sample holder as a randomly oriented powder (Poppe et al. 2001). Aggressive dry grinding may cause changes of phase and can lead to strains on the crystal structure that cause XRD line broadening or even the production of X-ray amorphous material.

As an example, the XRD spectrum for a full randomly oriented sample of a quarry tailings from a French site (aggregates and sand washing plant-the tailings represents the fine material, typically $<75 \mu \mathrm{m}$-separated by wet classification) is reported in Figure 4. 


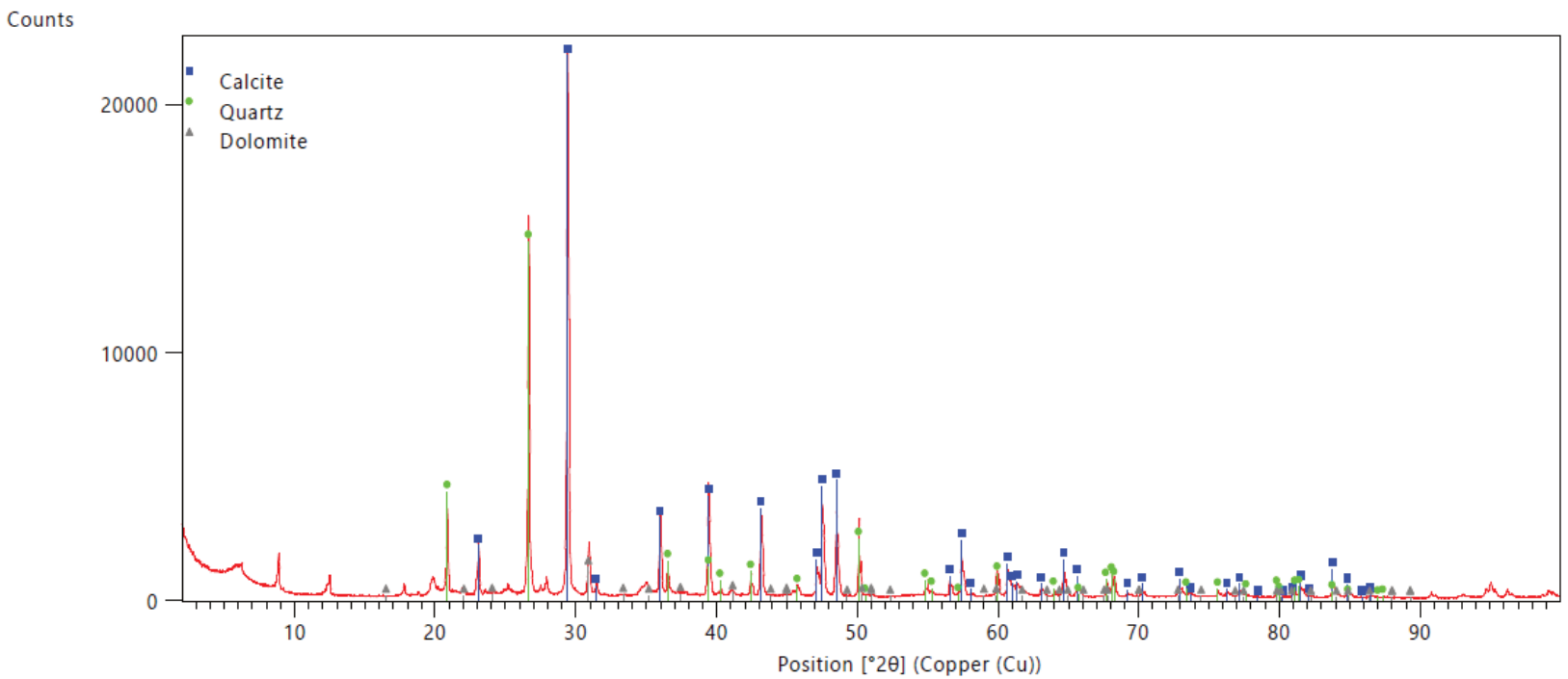

Figure 4 Spectrum of the total bulk sample

The phase identification can be done via software (in this case, Panalytical Highscore) that relates the full pattern with a databank of single crystalline phases (in this case, Crystallographic Open Database). At this stage, the main non-clayey phases can be identified (e.g. quartz, calcite and dolomite). To identify the remining phases, especially the clays, it is necessary to maximise the preferred orientation of the flake morphologies of clay minerals. For this purpose, the dry sample (a few grams) was slightly broken up in a mortar, resuspended in water and dispersed using ultrasound. The method for the separation of the fine fraction $(<2 \mu \mathrm{m})$ is based on Stokes's law (Cavalcante \& Belviso 2005), which is a numerical expression that describes a particle being pulled by gravity but whose fall is resisted by a viscous fluid; the equation is:

$$
V_{T}=\frac{g\left(d_{0}-d_{l}\right) D^{2}}{18 \eta}
$$

where:

$$
\begin{aligned}
& V_{T}=\text { the terminal velocity. } \\
& \eta \quad=\text { the liquid viscosity. } \\
& g \quad=\text { the force of gravity. } \\
& d_{p} d_{l}=\text { the density of the particle and the liquid. } \\
& D^{2}=\text { the particle diameter. }
\end{aligned}
$$

Using the relation:

$$
V=h / t
$$

where:

$$
\begin{aligned}
& V \quad=\text { the velocity of the particle. } \\
& h \quad=\text { the height of the cylinder in which there is the dispersion. } \\
& t \quad=\text { the time interval. }
\end{aligned}
$$

$t$ can be expressed by rearranging the Stokes's equation:

$$
t=\frac{18 \eta h}{g\left(d_{0}-d_{l}\right) D^{2}}
$$

where $t$ is the time taken for a particle of predetermined diameter to settle on the bottom of the suspension of height $h$. Since the falling time depends on $\eta$, which in turn is a function of the temperature, for a correct 
application of the Stokes's equation it is appropriate to measure the temperature of the suspension (Moore \& Reynolds 1997).

After the suspension is dispersed and settled, an aliquot of clay suspension may be withdrawn from above $5 \mathrm{~cm}$ in depth at the times and temperatures shown in Table 1. This step is repeated until an adequate amount of clay has been isolated. At this point the solid in the suspension is transferred, using a vacuum funnel onto a filter paper (pore size $<0.50 \mu \mathrm{m}$ ), in order to force the clay mineral particles, plate shaped, to lie flat, allowing the diagnostic basal diffraction to be recorded.

\section{Table 1 Settling time for gravity sedimentation of particles with diameter less than $2 \mu \mathrm{m}$}

\begin{tabular}{ll}
\hline Temperature $\left({ }^{\circ} \mathrm{C}\right)$ & Time \\
\hline 20 & $4 \mathrm{~h} 6 \mathrm{~min}$ \\
24 & $3 \mathrm{~h} 54 \mathrm{~min}$ \\
32 & $2 \mathrm{~h} 58 \mathrm{~min}$ \\
\hline
\end{tabular}

The clayey fraction is then deposited on the glass holder and analysed. The specimens are subsequently exposed to glycol and heat treatment.

The ethylene glycol treatment is extensively used as an auxiliary process to expand swelling clays. Whether or not a mineral expands, and the amount of any expansion, can provide essential supplementary information aiding clay mineral identification. Swelling clays include smectites, some mixed-layer clays, and vermiculite (Poppe et al. 2001).

Heat treatment at various temperatures (typically above $400^{\circ} \mathrm{C}$ ) are commonly used to help identify clay minerals by revealing changes in crystal structure spacings or loss of the structure. Depending on the temperature and the mineral species, these treatments can collapse the structure by dehydration, or in the case of other minerals, destroy the crystal structures (Poppe et al. 2001).

These steps are necessary to identify the clay phases present in the samples, because different untreated samples can show similar patterns.

Using the clay mineral identification flow diagram from the US Geological Survey and comparing the diffractograms of the clayey materials, appropriately treated, it is possible to identify the clays present. Figure 5 reports an example of a qualitative analysis of the fine fraction.

In Figure 5, the peaks of sequence 1 vary after glycolation and further after heat treatment; with the additional information of the bulk XRD analyses, with the comparison of the sheets of the crystalline phases and through the information obtained from the US Geological Survey, it is possible to attribute this sequence to the presence of smectite. The peaks of sequence 2 remain in the same position and with the information mentioned above, together with the data from the bulk spectrum, it is possible to attribute this sequence to the presence of illite. In the same way, the peaks of sequence 3 remain in the same position after glycolation and heat treatment at $400^{\circ} \mathrm{C}$, but after heat treatment at $550^{\circ} \mathrm{C}$ the peak collapses; therefore, it is possible to attribute this sequence to the presence of chlorite (Poppe et al. 2001). 


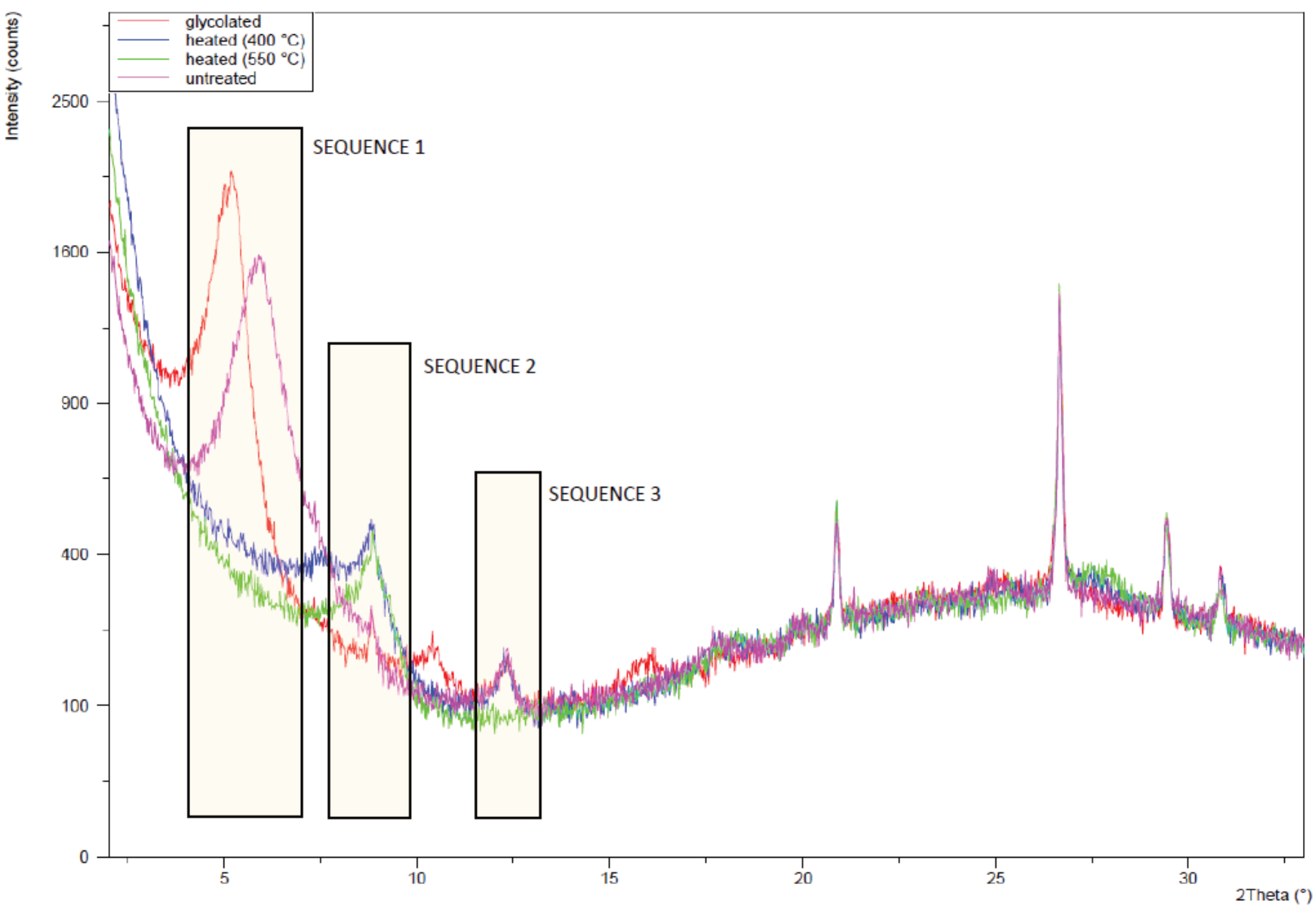

Figure 5 Spectra oriented aggregates with different treatments

Once all the phases present (crystalline phases and clayey phases) have been identified, the quantitative analysis is carried out using a Rietveld refinement method, based on a least squares approach, to refine a theoretical line profile until it matches the measured profile. Different software is available for this purpose; in this work Quanto software has been used (Altomare et al. 2001).

To evaluate the correlation between clay content and filterability, the parameter $\alpha_{\text {cST }}$ has been used, defined as:

$$
\alpha_{C S T}=\frac{\text { Slurry solid concentration }}{C S T}
$$

where:

Slurry solid concentration is the solid content in the slurry, expressed as $\mathrm{g} / \mathrm{L}$.

CST is the capillary suction time.

Capillary suction time is a quick and reliable measure directly related to the cake-specific resistance, determined using a special timer apparatus that measures the time for the liquid phase to advance between radially separated electrodes when a fixed area of special filter paper is exposed to the suspension (Chen et al. 1996).

In a general manner, the higher the $\alpha_{\text {CST }}$ the better the filterability (empirically speaking, $\alpha_{C S T}$ values below three result in filter press cycle time higher than one hour). 


\section{Data and results}

The steps focused on creating a dataset of mineralogical phase quantification of quarry tailings (e.g. aggregates production, limestone extraction, demolition plants). These samples are characterised by high clay contents that are related to low filtration rates (less than two cycles per hour typically achievable with a recessed plate pack configuration, as comparison can be considered that tailings filtration with filterpress can reach four cycles per hour throughput), and because of this they are particularly suitable for this purpose, in particular considering the comprehensive case history database of Diemme Filtration's research and development department.

Preliminary results of these characterisations are reported in Figure 6.

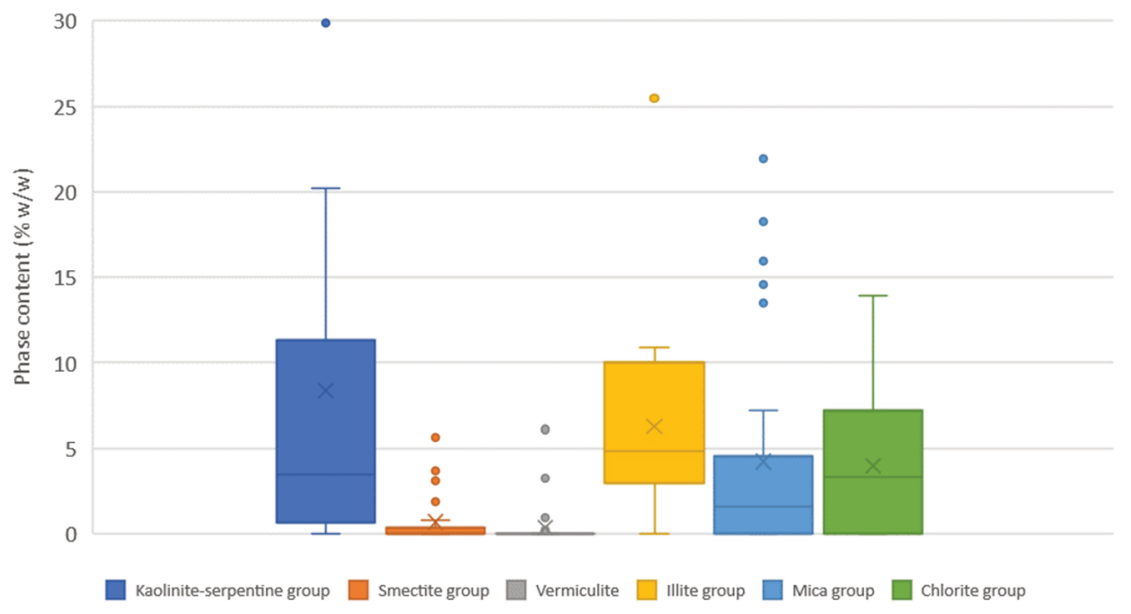

Figure 6 Box plot of phyllosilicates phases content, by clay group

Figures 7 and 8 show the correlation between clays content and filterability (i.e. $\left.\alpha_{C S T}\right)$. Looking through the data, the smectite group clays seem to play a bigger role in increasing the cake-specific resistance (therefore lowering the filterability). While there's no significant correlation between $\alpha_{C S T}$ and overall clay content, by taking into account the smectite fraction, a good correlation is detectable.

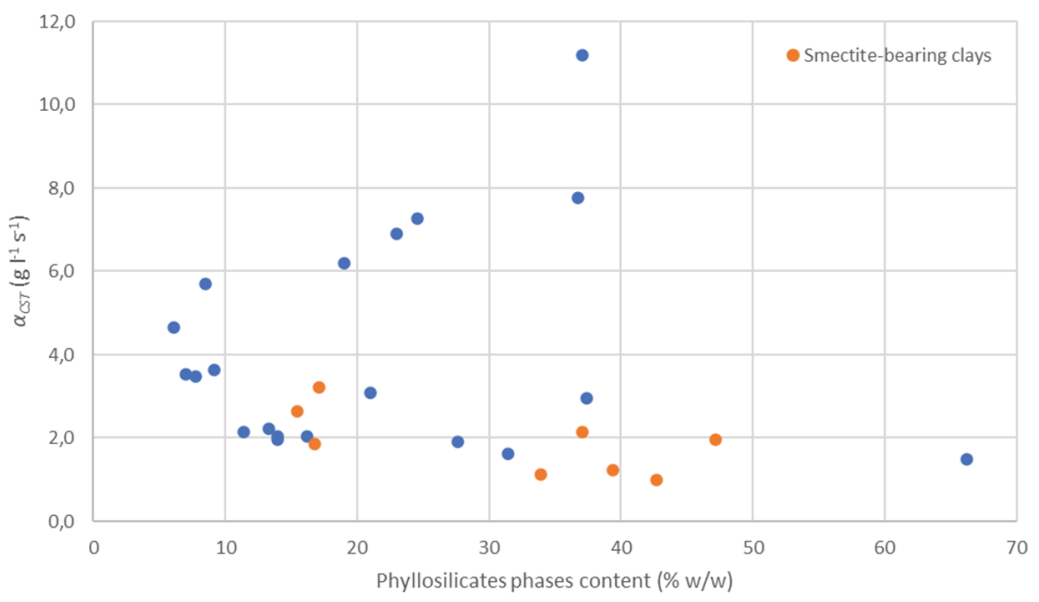

Figure 7 Relation between $\alpha_{C S T}$ and clay phases content 


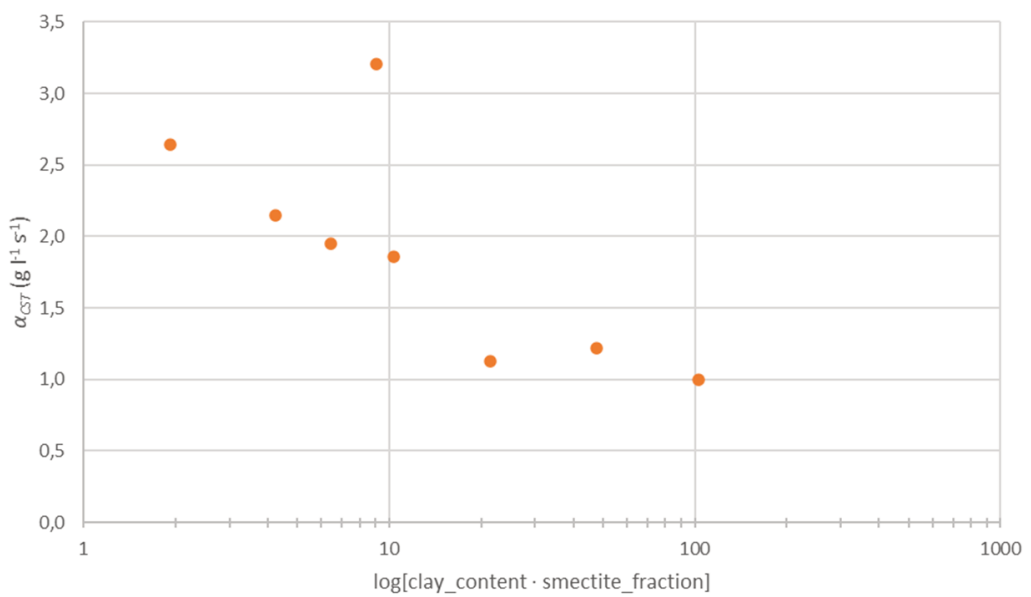

Figure 8 Relation between $\alpha_{C S T}$ and clay phases content, taking into account the smectite fraction

All cases where a smectite mineral is present, even in small concentrations (less than $1 \% \mathrm{w} / \mathrm{w}$ ), are characterised by low filterability, with a dramatic effect on filtration time. No similar correlations considering other clay groups have been highlighted.

To confirm this preliminary evidence, a few case studies of mine tailings have been analysed. The mineralogical characterisation of mine tailings presents a high complexity, mainly due to the high number of phases (both phyllosilicates and others) and the low amount of clays present that makes their separation from the bulk difficult, requiring a further step of pre-concentration (e.g. by centrifugation).

The results relating to three different tailings are presented here. Two are iron ore tailings (hematite tailings is marked as \#1 and pyrite tailings as \#2) and one is from a lithium extraction project.

Table 2 shows the clayey phases and the total amount of clay, while Table 3 shows the main particle size distribution statistics (from laser low-angle scattering analysis of liquid dispersion) and $\alpha_{C S T}$ values for each tailings.

Table 2 Percentage composition and total amount of clays

\begin{tabular}{llllll}
\hline Sample & Kaolins & Smectites & Micas & Chlorites & Total clay \\
\hline Iron ore tailings \#1 & 5.14 & 0 & 0 & 0 & 5.14 \\
Iron ore tailings \#2 & 0 & 0 & 1.55 & 0 & 1.55 \\
Lithium tailings & 1.88 & 4.36 & 0.44 & 0.69 & 7.37 \\
\hline
\end{tabular}

Table 3 Particle size distribution statistics and $\alpha_{C S T}$

\begin{tabular}{llllll}
\hline Sample & $\%<2 \mu \mathrm{m}$ & $\mathrm{d}[10] \mu \mathrm{m}$ & $\mathrm{d}[50] \mu \mathrm{m}$ & $\mathrm{d}[90] \mu \mathrm{m}$ & $\boldsymbol{\alpha}_{\text {CST }}$ \\
\hline Iron ore tailings \#1 & 42.1 & 0.691 & 2.45 & 12.1 & 4.8 \\
Iron ore tailings \#2 & 2.76 & 9.13 & 80.8 & 229 & 41.8 \\
Lithium tailings & 13.6 & 1.58 & 17 & 103 & 0.8 \\
\hline
\end{tabular}

These samples show different behaviour in terms of filterability. While both iron ore tailings can be dewatered in a relatively reasonable time (less than 20 minutes for cake build-up), the lithium tailings presents very long filtration cycles (more than 120 minutes with a recessed plate configuration). This observation is at odds with the particle size distribution data, as reported in Table 3 and Figure 9 (where the overall curves of lithium tailings and iron ore tailings \#1 overlayed). Iron ore tailings \#1 has a monophasic distribution with $42 \%$ of the particles below $2 \mu \mathrm{m}$; much more than the lithium tailings where its fraction 
equals $13.6 \%$, despite a relatively similar phyllosilicate content, due to the presence of a fine hematite fraction. These data show how important it is to distinguish between clay-sized particles and true clay mineral particles (Jewell \& Fourie 2015).

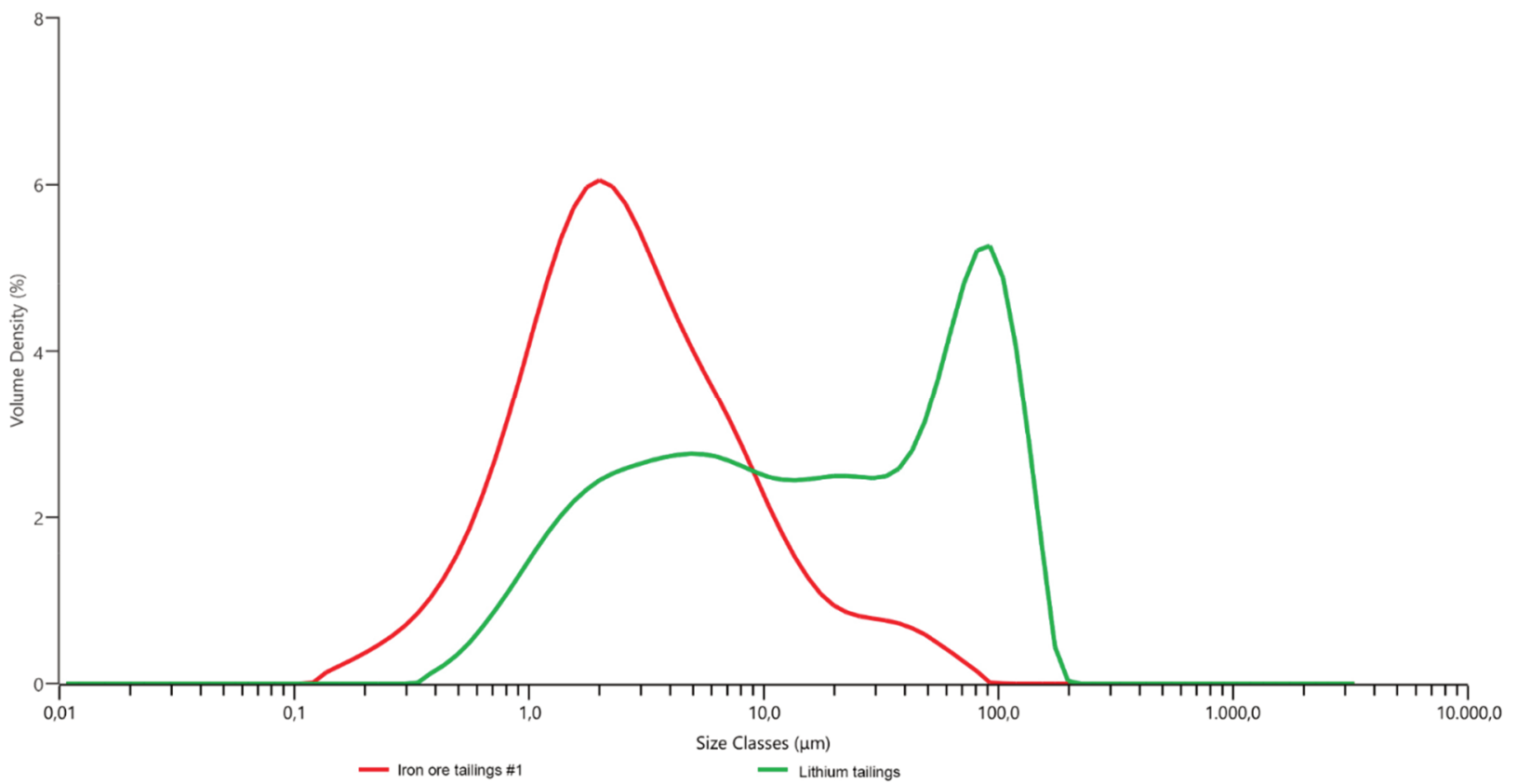

Figure 9 Overlay of particle size distribution of iron ore tailings \#1 and lithium tailings

The comparison between the two iron ore tailings is also interesting. For iron ore tailings \#2, the combination of various factors, including a low percentage of fine and clayey material and the absence of smectites, leads to excellent filterability with very low compaction times and high permeability of the cake, making the desaturation stage particularly profitable. Based on a bench-scale filtration test, it is possible to estimate an increase of four percentage points in terms of dryness by performing an air drying stage on this tailings (in comparison with the cake obtained avoiding desaturation), while for iron ore tailings \#1 this increase is almost negligible (0.4\%).

\section{$4 \quad$ Practical implications}

From the results presented above it is clear how some clay phases play a crucial role in affecting the throughput achievable by a filter press (and, in a general matter, a solid-liquid separation technology).

These aspects are of the utmost importance considering the current increase in throughput demand of mining projects with the consequential development of extremely high-capacity filter presses. Diemme Filtration has designed the new GHT.5000.F filter press (Figure 10), that will feature a cake volume of up to $71 \mathrm{~m}^{3}$ and a total filtration area of up to $2,900 \mathrm{~m}^{2}$. The first unit will be installed on a copper mine and will filter approx. 8,000 tonnes per day of dry solid. This new filter is highly configurable and can be precisely tuned to suit the particular nature of the feed slurry and the cake moisture target in order to optimise capex and opex. The knowledge of the type and content variability of clay is one of the key factors that can help set up the machine in order to maximise the throughput and handle fluctuations, by proper selection of chamber thickness, plate type (membrane or recessed), application of cake blowing phase and appropriate selection of ancillaries (pumps, compressors for cake blowing and squeezing). 


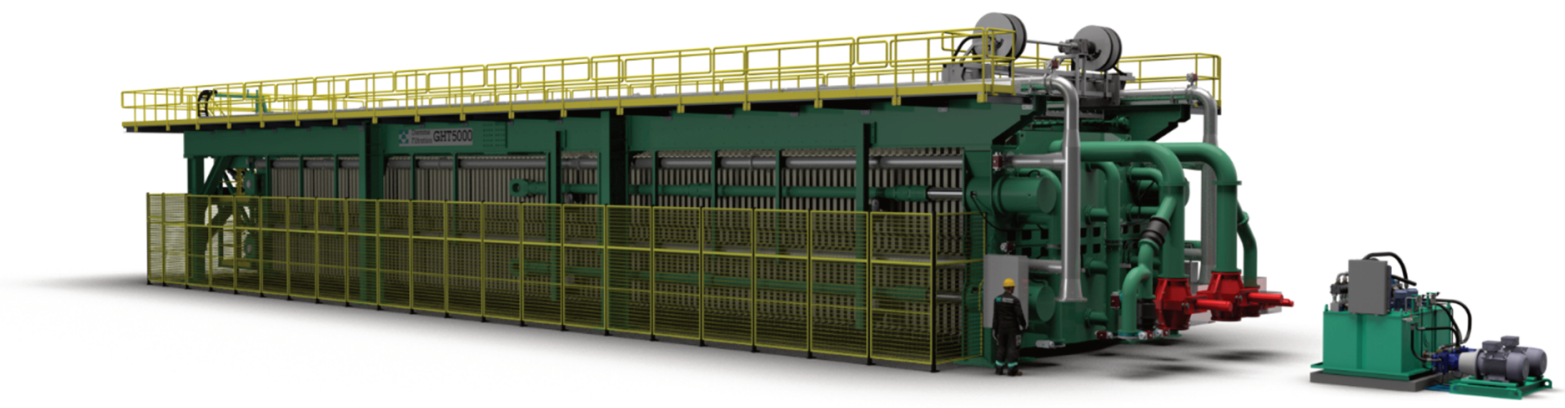

Figure 10 Diemme Filtration GHT.5000F

\section{Conclusion}

The analysis of clay phases is a complex technique that requires both the advanced use of XRD techniques and spectra modelling preparation methods. These should be appropriately developed considering the high complexity of the tailings solid matrix. The results presented here clearly show that, despite objective difficulties, this analytical approach is crucial for a comprehensive understanding of the tailings behaviour in terms of filterability and dewaterability. Limiting the characterisation to particle size distribution, elemental analysis and mineralogical quantification without identifying the individual clayey phases can lead to a partial overview of the sample with potential issues such as wrong equipment sizing and poor process control.

An important future development of these preliminary results is the increase in case studies in order to create an adequate dataset and define trends that describe and quantify the impact of the clay content on the filtration process (e.g. cake-specific resistance, desaturation and deliquoring performance). In addition, correlations with surface properties such as zeta potential, that can affect particle dispersion or agglomeration and consequently the cake build-up process, will be investigated.

\section{References}

Altomare, A, Burla, MC, Giacovazzo, C, Guagliardi, A, Moliterni, AGG, Polidori, G \& Rizzi, R 2001, 'Quanto: a Rietveld program for quantitative phase analysis of polycrystalline mixtures', Journal of Applied Crystallography, vol. 34, pp. 392-397.

Cavalcante, F \& Belviso, C 2005, 'Trattamenti e metodi di preparazione di campioni di materiali argillosi per l'analisi diffrattometrica', Argille e Minerali delle Argille, vol. 5, pp. 23-50.

Chen, GW, Lin, WW \& Lee, DJ, 'Capillary suction time (CST) as a measure of sludge dewaterability', Water Science and Technology, vol. 34, pp. 443-448.

Jewell, RJ \& Fourie, AB 2015, Paste and Thickened Tailings - A Guide, 3rd edn, Australian Centre for Geomechanics, Perth.

McFarlane, A, Bremmell, K \& Addai-Mensah, J 2006, 'Improved dewatering behavior of clay minerals dispersion via interfacial chemistry and particle interactions optimization', Journal of Colloid and Interface Science, vol. 293, pp. 116-127.

Moore, DM \& Reynolds, RC, Jr 1997, X-Ray Diffraction and the Identification and Analysis of Clay Minerals, 2nd edn, Oxford University Press, Oxford.

Ndlovu, B, Forbes, E, Farrokhpay, S, Becker, M \& Bradshaw, D 2014, A preliminary rheological classification of phyllosilicate group minerals, Mineral Engineering, vol. 55, pp. 190-200.

Poppe, LJ, Paskevich, VF, Hathaway, JC \& Blackwood, DS 2001, A Laboratory Manual for X-Ray Powder Diffraction, US Geological Survey Open-File Report 04-041, US Geological Survey, Reston.

Tournassat, C, Steefel C, Bourg, I \& Bergaya, F 2015, Natural and Engineered Clay Barriers, 1st edn, vol. 6, Elsevier, Amsterdam.

United Nations Environment Programme International Resources Panel 2021, United Nations Environment Programme International Resource Panel Global Material Flows Database, https://www.resourcepanel.org/global-material-flows-database 
